\title{
Article \\ Genome Mining and Analysis of PKS Genes in Eurotium cristatum E1 Isolated from Fuzhuan Brick Tea
}

\author{
Xiaoxiao Guo ${ }^{1,2}$, Fusheng Chen ${ }^{1,2}$, Jiao Liu ${ }^{3,4}$, Yanchun Shao ${ }^{1,2}$, Xiaohong Wang ${ }^{1,2, *}$ and Youxiang Zhou ${ }^{3,4, *}$ \\ 1 College of Food Science and Technology, Huazhong Agricultural University, Wuhan 430070, China; \\ guoxiaoxiao0321@aliyun.com (X.G.); chenfs@mail.hzau.edu.cn (F.C.); yanchunshao@mail.hzau.edu.cn (Y.S.) \\ 2 Key Laboratory of Environment Correlative Dietology, Ministry of Education, Huazhong Agricultural \\ University, Wuhan 430070, China \\ 3 Institute of Agricultural Quality Standards and Testing Technology Research, Hubei Academy of Agricultural \\ Sciences, Wuhan 430064, China; babojiao@126.com \\ 4 Hubei Key Laboratory of Nutritional Quality and Safety of Agro Products, Wuhan 430064, China \\ * Correspondence: wxh@mail.hzau.edu.cn (X.W.); zhou_youxiang@aliyun.com (Y.Z.); \\ Tel./Fax: +86-27-87282111 (X.W.); +86-27-87389465 (Y.Z.)
}

check for updates

Citation: Guo, X.; Chen, F.; Liu, J.; Shao, Y.; Wang, X.; Zhou, Y. Genome Mining and Analysis of PKS Genes in Eurotium cristatum E1 Isolated from Fuzhuan Brick Tea. J. Fungi 2022, 8, 193. https://doi.org/10.3390/ jof8020193

Academic Editor: Anna Muszewska

Received: 11 January 2022

Accepted: 10 February 2022

Published: 16 February 2022

Publisher's Note: MDPI stays neutral with regard to jurisdictional claims in published maps and institutional affiliations.

Copyright: (C) 2022 by the authors. Licensee MDPI, Basel, Switzerland. This article is an open access article distributed under the terms and conditions of the Creative Commons Attribution (CC BY) license (https:// creativecommons.org/licenses/by/ $4.0 /)$.

\begin{abstract}
Eurotium cristatum as the dominant fungi species of Fuzhuan brick tea in China, can produce multitudinous secondary metabolites (SMs) with various bioactivities. Polyketides are a very important class of SMs found in E. cristatum and have gained extensive attention in recent years due to their remarkable diversity of structures and multiple functions. Therefore, it is necessary to explore the polyketides produced by E. cristatum at the genomic level to enhance its application value. In this paper, 12 polyketide synthase (PKS) genes were found in the whole genome of E. cristatum E1 isolated from Fuzhuan brick tea. In addition, the qRT-PCR results further demonstrated that these genes were expressed. Moreover, metabolic analysis demonstrated E. cristatum E1 can produce a variety of polyketides, including citreorosein, emodin, physcion, isoaspergin, dihydroauroglaucin, iso-dihydroauroglaucin, aspergin, flavoglaucin and auroglaucin. Furthermore, based on genomic analysis, the putative secondary metabolites clusters for emodin and flavoglaucin were proposed. The results reported here will lay a good basis for systematically mining SMs resources of E. cristatum and broadening its application fields.
\end{abstract}

Keywords: Eurotium cristatum; Fuzhuan brick tea; whole genome; polyketide synthase; secondary metabolites; emodin; flavoglaucin

\section{Introduction}

Fuzhuan brick tea is one of traditional microbial fermented teas in China [1]. Historically, it has been a daily necessity for ethnic minorities in China's Qinghai, Xinjiang, Tibet, Inner Mongolia and other border regions [2]. During the manufacturing process of Fuzhuan brick tea, fungal fermentation is the unique step in achieving particular characteristics and pharmacological health benefits [3]. E. cristatum, as the dominant fungus involved in this process, can form yellow cleistothecium, which looks like a golden flower, and is therefore commonly known as "Jinhua" by providers and consumers in China [4,5]. Due to the distinctive influence on the color, aroma, and flavor of Fuzhuang brick tea by "Jinhua", the quality and the amount of "Jinhua" were considered as the important parameters to evaluate the quality of Fuzhuan brick tea [6].

In the 1940s, the first study regarding the identification of the dominant fungi in Fuzhuan brick tea was reported. In 1990, according to the international rules of nomenclature for algae, fungi, and plants, this fungus was identified as Eurotium cristatum (anamorph: Aspergillus spiculosus, synonym: Aspergillus cristatus) by observing its morphology under a microscope and scanning electron microscope [7].

The fermentation of E. cristatum gives Fuzhuan brick tea specific color, aroma, taste, and some useful physiological functions for human health such as anti-hyperlipidemia, 
anti-obesity, treating cardiovascular diseases, helping digestion, etc. [8,9]. Previous studies implied that these interesting characteristics were ascribed to the secreted SMs from E. cristatum. However, the mechanisms for these potential functional SMs at the genomic, transcriptional, and metabolic level are not yet clear.

Fungal polyketides (PKs) are very important secondary metabolites with diverse structures, functional diversities, and a wide range of biological activities [10]. E. cristatum is a kind of common indoor filamentous fungi, which is renowned for producing multitudinous secondary metabolites with various bioactivities [11]. At least 25 secondary metabolites in E. cristatum were identified in previous reports [12-15]. According to their chemical structures, these secondary metabolites can be classified into four types, benzaldehyde derivatives (Bds), anthraquinone derivatives, indole derivatives, and other compounds, respectively (as shown in Figure 1). About $70 \%$ of these SMs are polyketides, mainly including benzaldehyde and anthraquinone derivatives. To date, studies on these compounds have only focused on their structures and bioactivities. Therefore, the research on SMs especially PKs produced by E. cristatum is still in its infancy, and the mining is far from enough. In addition, the genetic and molecular basis for the biosynthesis of these PKs in E. cristatum is still unclear.

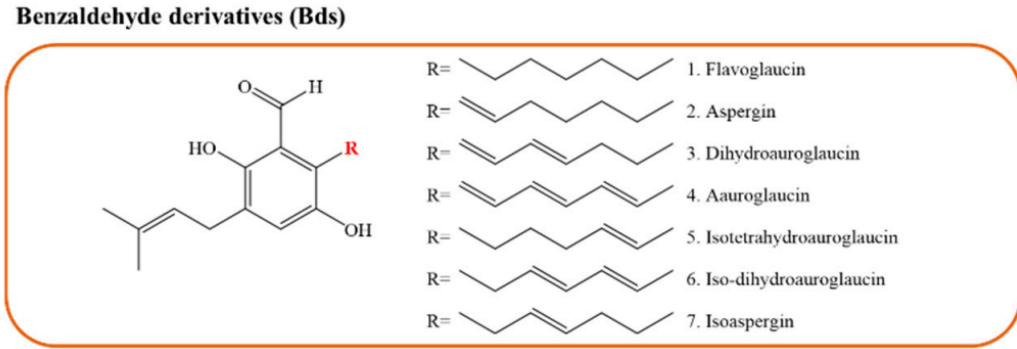

Anthraquinone derivatives

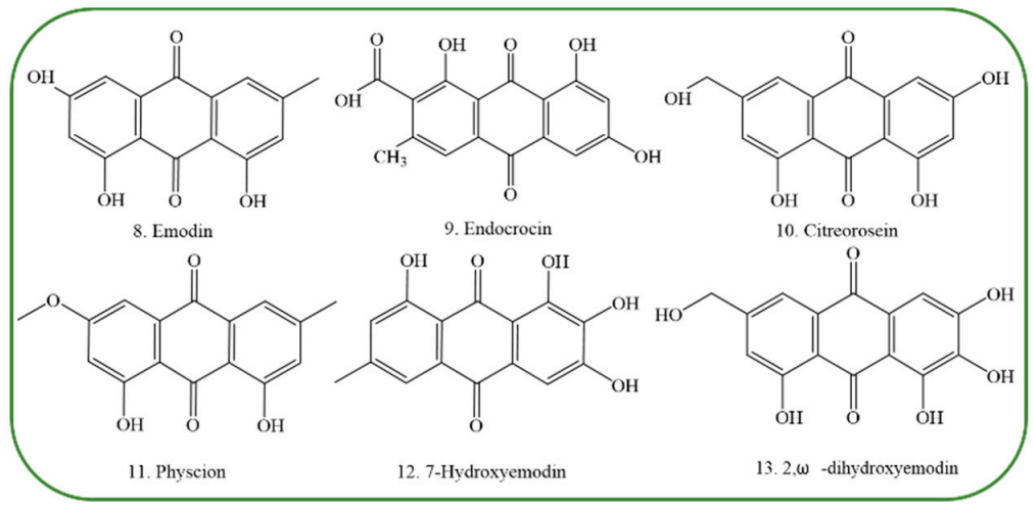

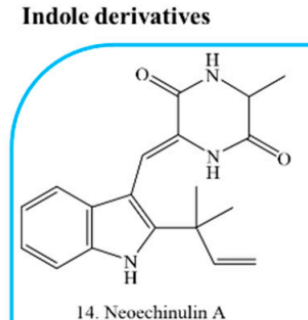
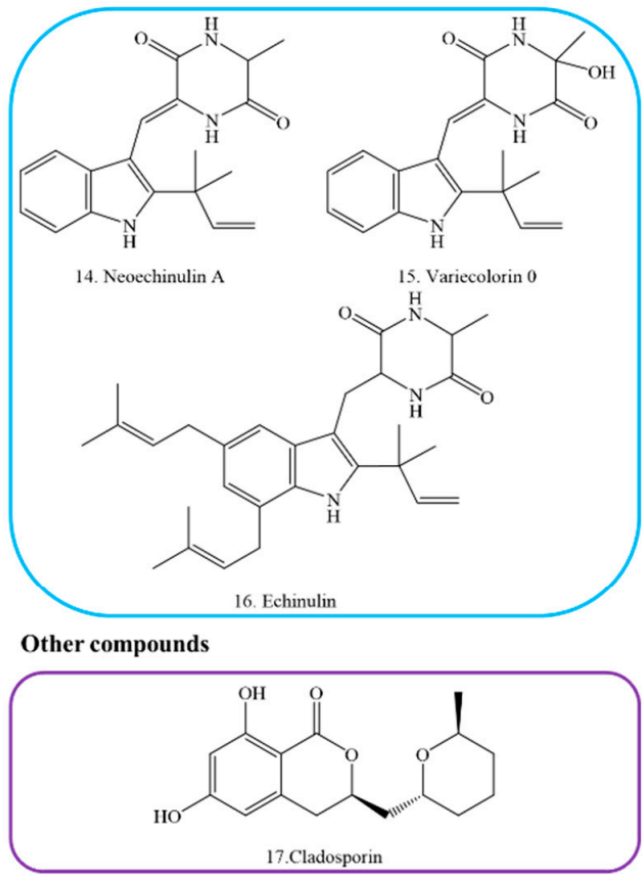

Figure 1. Chemical formulations of some common secondary metabolites in Eurotium cristatum.

In this study, the genome of E. cristatum E1 isolated from Fuzhuan brick tea was obtained, all the PKS genes in this fungus were predicted and the expression level of these genes was analyzed. Then, SMs were detected and identified by UPLC and UPLC-MS/MS. The putative emodin and flavoglaucin biosynthetic gene cluster were proposed, and the comparison with known gene clusters was performed. In general, this study will have important theoretical guiding value for elucidating the diversity of secondary metabolites produced by E. cristatum, and as far as possible to provide a basis for the development and application of E. cristatum.

\section{Materials and Methods}

\subsection{Strains, Growth Conditions and Genomic DNA Extraction}

E. cristatum E1 (CCTCC M20211112) was isolated from Fuzhuan brick tea in Yi Yang City, Hunan Province, China. The fungus was cultured on MYA medium (malt extract 
powder $20 \mathrm{~g}$, yeast extract powder $5 \mathrm{~g}$, sucrose $30 \mathrm{~g}$, agar $20 \mathrm{~g}$, and water $1000 \mathrm{~mL}$ ) with cellophane at $28^{\circ} \mathrm{C}$ for 3 days. Mycelia were gathered from cellophane and crushed in a mortar with liquid nitrogen. The CTAB method was used to extract the genomic DNA [16].

\subsection{Genome Sequencing, Assembly and Annotation}

The extracted DNA was detected by agarose gel electrophoresis and quantified by FastQC [17]. The genome was sequenced by single-molecule real-time (SMRT) technology. Sequencing was performed at the Beijing Novogene Bioinformatics Technology Co., Ltd. The low-quality reads were filtered by the SMRT Link v5.0.1 [18] and the filtered reads were assembled to generate one contig without gaps.

The Augustus 2.7 program was used to predict the coding gene [19]. Gene function was predicted by using the KOG (Clusters of Eukaryotic Orthologous Groups) database. The genome-wide circle was drawn by using Circos V0.64 software.

\subsection{Phylogenetic Relationships and Comparative Genomic Analysis}

Taxonomy was performed through the construction of a phylogenetic tree based on the alignment of partial $\beta$-tubulin (BenA), calmodulin (CaM) and RNA polymerase II second largest subunit (RPB2) genes. Homologous sequences were identified using BlastN against the nr NCBI database [20]. The accession number of used genes is shown in Supplementary Table S1. Sequences were aligned by ClustalW in MEGA 5.05 [21]. All positions containing gaps and missing data were eliminated from the dataset (complete deletion option). Phylogenetic inference was performed in MEGA 5.05 with the NeighborJoining approach with 100 bootstrap replicates [21].

Orthologous genes were searched between E. cristatum E1 and A. cristatus GZAAS 20.1005 genomes using the OrthoFinder program (version 2.5.4) [22]. The two genomes were aligned with the Progressive Mauve algorithm by using MAUVE (version 2.3.0) [23].

\subsection{Identification of Biosynthetic Gene Clusters}

Biosynthetic gene clusters (BGCs) were analyzed by the antiSMASH 5, using the standard parameters with options of fungal BGC scanning setups [24]. The Known Cluster Blast module was enabled to compare predicted BGCs with those validated and characterized BGCs deposited on the Minimal Information about a Biosynthetic Gene cluster (MIBiG) database [25].

\subsection{Identification of Polyketide Synthase Genes}

The minimal structure of fungal PKS only requires the highly conserved sequences of $\beta$-ketosynthase (KS), acyltransferase (AT) and acyl carrier protein (ACP) domains. Thus, the three domains are used in screening for PKSs. Then, the Pfam database [26] and NCBI CDD database [20] were used to scan for significant domains of these proteins. The conserved functional domains present in PKSs were further confirmed using Synthaser (v1.1.0) [27], and the function of these genes was predicted using NCBI BLASTP with an E-value of $<1 \times 10^{-10}$ after setting up the online BLAST database [20].

\subsection{The Relative Expression Level Analysis of PKS Genes}

RNA was isolated from mycelia grown on cellophane membranes covering PDA plates using TransGen Biotech TransZol Up Plus RNA Kit (TransGen, Beijing, China). RNA is retrotranscribed into cDNA using Vazyme HiScript II Q RT SuperMix for qPCR (+gDNA wiper) (Vazyme, Nanjing, Jiangsu, China).

Quantitative real-time RT-PCR (qRT-PCR) was performed by qTOWER 2.2 Real-Time PCR Systems (Analytik Jena, Jena, Germany). Relative expression was evaluated with $12.5 \mu \mathrm{L}$ Vazyme AceQ Universal SYBR qPCR Master Mix (Vazyme, Nanjing, Jiangsu, China), $1.0 \mu \mathrm{L}$ of $2.5 \mu \mathrm{M}$ forward primer, $1.0 \mu \mathrm{L}$ of $2.5 \mu \mathrm{M}$ reverse primer, and $2.0 \mu \mathrm{L}$ of template cDNA. Thermal cycling conditions comprised initial denaturation at $94{ }^{\circ} \mathrm{C}$ for $1 \mathrm{~min}$ followed by 40 amplification cycles at $95^{\circ} \mathrm{C}$ for $15 \mathrm{~s}, 58^{\circ} \mathrm{C}$ for $20 \mathrm{~s}$, and $72{ }^{\circ} \mathrm{C}$ for $20 \mathrm{~s}$ with 
a final extension step at $72{ }^{\circ} \mathrm{C}$ for $5 \mathrm{~min}$ [16]. $\beta$-actin was used as the reference gene. The primers used in this section are listed in Supplementary Table S2.

\subsection{Analysis of Secondary Metabolites Produced by Eurotium cristatum E1}

Two hundred microliters of fresh spore suspensions $\left(10^{5} / \mathrm{mL}\right)$ of E. cristatum E1 was inoculated on cellophane membranes covering PDA plates and cultivated at $28{ }^{\circ} \mathrm{C}$ for 11 days. The mycelia were collected and freeze-dried, and the media were dried to a constant weight in a $37{ }^{\circ} \mathrm{C}$ oven. Twenty milligrams of mycelia or $50 \mathrm{mg}$ media was extracted by $1.5 \mathrm{~mL} 80 \%$ methanol with ultrasound for $20 \mathrm{~min}$. After that, the samples were centrifuged (Heal Force Neofuge 15R, Shanghai, China) at 12,000 $\times \mathrm{g}$ for $10 \mathrm{~min}$ to collect the supernatant.

Mycelia and media were analyzed by ultra-performance liquid chromatographyphotodiode array detector (UPLC-PDA) and UPLC-tandem mass spectrometry (UPLCMS/MS). UPLC analysis was conducted on a Waters ACQUITY UPLC system equipped with a PDA detector (Waters, Milford, MA, USA) with an ACQUITY BEH C18 column $(2.1 \mathrm{~mm} \times 100 \mathrm{~mm}, 1.7 \mu \mathrm{m})$. The flow rate was $0.3 \mathrm{~mL} / \mathrm{min}$. Mobile phases consisted of A, $\mathrm{B}$ and $\mathrm{C}$, which were $0.1 \%$ formic acid, water, and acetonitrile, respectively. The gradient procedure was run as follows: A is always kept at 10\%, 35\% C for $3 \mathrm{~min}$, from $35 \% \mathrm{C}$ to $70 \% \mathrm{C}$ in $15 \mathrm{~min}$, then from $70 \% \mathrm{C}$ to $90 \% \mathrm{C}$ in $5 \mathrm{~min}$, and lastly, kept at $35 \% \mathrm{C}$ for $3 \mathrm{~min}$. Ultraviolet absorbance was detected at 200 to $600 \mathrm{~nm}$ wavelength. The column temperature was $40^{\circ} \mathrm{C}$. The injection volume was $2 \mu \mathrm{L}$.

UPLC-MS/MS analysis was operated on a Waters ACQUITY UPLC system with Xevo tandem quadrupole mass spectrometer (Waters, Milford, MA, USA). The UPLC conditions were the same as described above. UPLC and mass spectrometry were performed by the methods established in our laboratory [28].

Emodin (Sigma-Aldrich, Shanghai, China), physcion (Sigma-Aldrich, Shanghai, China), and flavoglaucin (Biobiopha, Yunnan, China) were used as standards.

\subsection{Comparison of Emodin and Flavoglaucin Gene Clusters}

The function of genes from emodin (A2490) and flavoglaucin (A7192) gene clusters was predicted using NCBI BLASTP [20]. The alignment and visualization of homologous gene clusters in E. cristatum E1 and other known clusters were carried out using Clinker [29].

\section{Results}

\subsection{The Basic Information of Whole Genome}

The whole genome of E. cristatum E1 was sequenced by the combination of thirdgeneration sequencing (TGS) and next-generation sequencing (NGS) technology. A total of $6577 \mathrm{Mb}$ raw sequence data were generated. The total assembly size of the genome was $28.06 \mathrm{Mb}$, which was assembled into 9 contigs, with an N50 length of $3.56 \mathrm{Mb}$ (Figure 2, Table 1). A total of 9226 genes were predicted via ab initio and homology-based analyses by the Augustus program (version 2.7). The total sequence of these coding genes was $14.29 \mathrm{Mb}$, accounting for $50.93 \%$ of the total genome sequence, with an average coding length of $1549 \mathrm{bp}$, and the GC content was $49.68 \%$ (Table 1).

Table 1. General feature of E. cristatum E1 genome and A. cristatus GZAAS 20.1005 genome.

\begin{tabular}{ccc}
\hline Genome & E. cristatum E1 & A. cristatus GZAAS 20.1005 \\
\hline General information & & \\
Size $(\mathrm{Mb})$ & 28.06 & 27.9 \\
Number of contigs/scaffolds & 9 & 68 \\
N50 (bp) & $3,564,179$ & $2,308,221$ \\
G + C content (\%) & 49.72 & 49.86 \\
Coding $(\%)$ & 50.93 & 51.92 \\
Protein-coding genes & 9226 & 10,136 \\
Mean gene length (bp) & 1549 & 1573 \\
\hline
\end{tabular}




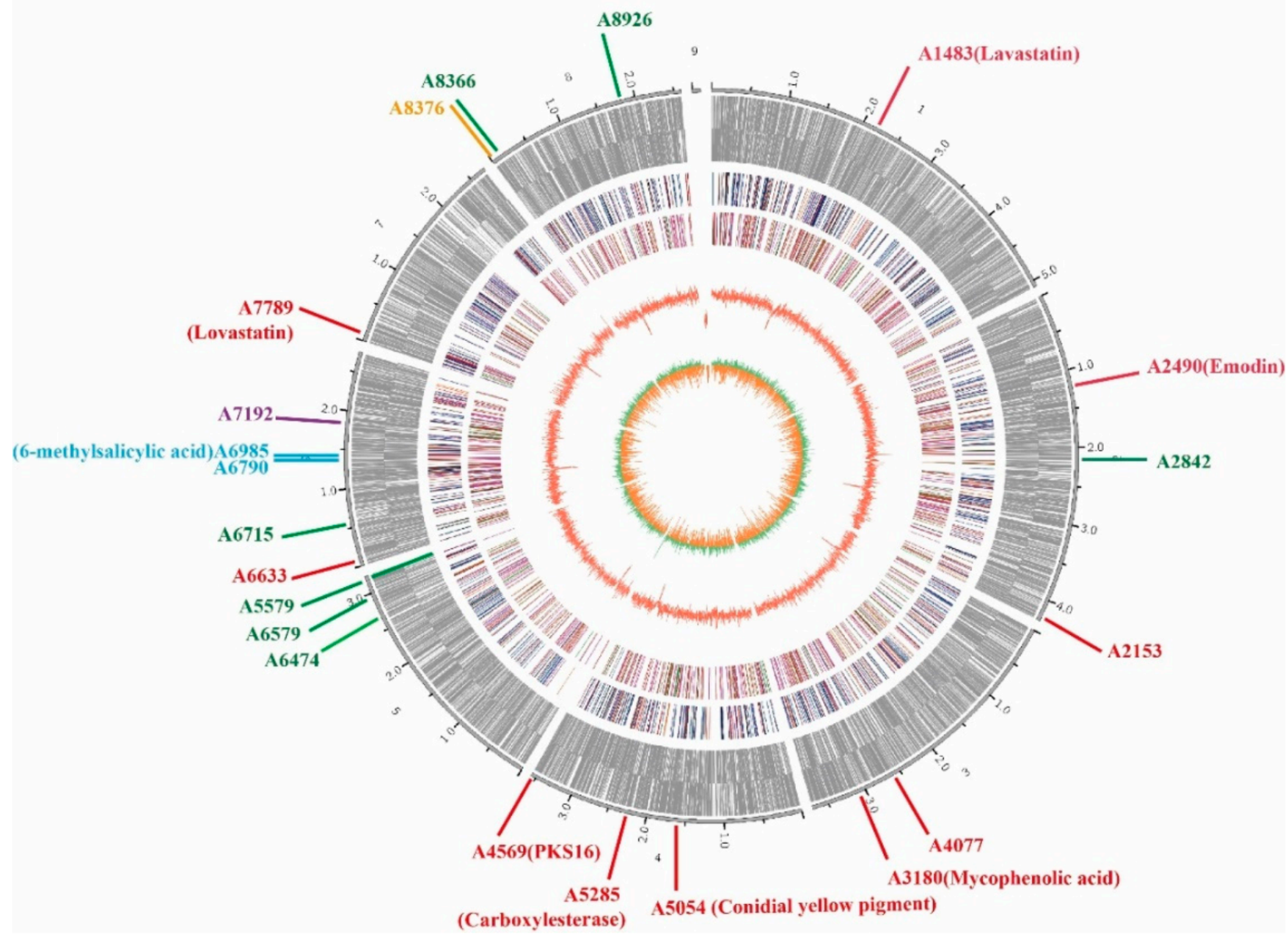

Figure 2. Genome map of Eurotium cristatum E1. From the outside to the inside: the first circle is the genome contig; the second circle is the gene density of the sense strand; the third circle is the gene density of the antisense strand; the fourth and fifth circles are the KOG annotation results; the sixth circle is the GC content calculated with $2000 \mathrm{bp}$ as a window on each contig; the seventh circle is the GC offset. The polyketide synthase (PKS) and nonribosomal peptide synthase (NRPS) genes were shown in the genome map of E. cristatum E1. The red represents PKS gene. The green represents NRPS gene. The blue represents hybrid PKS and NRPS gene. The purple and orange represent indole-PKS and indole-NRPS gene, respectively.

The gene functional annotation was carried out using the Clusters of Eukaryotic Orthologous Groups (KOG) database. KOG database is a direct homology database for eukaryotes. It defines four main functional categories: cellular processes, information storage/processing, metabolism, and function poorly characterized, which are further subdivided into 25 categories [30]. The amino acid sequences of genes in the genome were compared with the KOG database by the Diamond software to obtain the functional annotation, and the result is shown in Supplementary Figure S1. The genes in the cellular processes and signaling were mainly annotated to $\mathrm{O}$ (posttranslational modification, protein turnover, chaperones, 225), U (intracellular trafficking, secretion, and vesicular transport, 125), T (signal transduction mechanisms, 123). The genes involved in information storage/processing were mainly related to translation, ribosomal structure, and biogenesis (J, 204). The metabolism analysis suggested that the genes were mainly attributed to C (energy production and conversion, 187) and $\mathrm{E}$ (amino acid transport and metabolism, 179). KOG analysis showed that about 844 (37.5\%) of the 2248 genes assigned to KOG functional categories were involved in metabolism. 


\subsection{Phylogenetic Relationships and Comparative Genomic Analysis}

A phylogenetic tree was constructed based on the concatenated multiple sequence alignments (MSA) of partial $\beta$-tubulin (BenA), calmodulin (CaM), and RNA polymerase II second largest subunit (RPB2) genes, and identified E1 as Eurotium cristatum (Supplementary Figure S2a). This agrees with the taxonomic assignment based on morphological characterization profiling (Supplementary Figure S2b). Furthermore, phylogenetic results confirm that the sequenced strain E1 is genetically closer to Eurotium chevalieri.

In 2013, the whole genome of Aspergillus cristatus (A. cristatus GZAAS 20.1005, GenBank: GCA_001717485.1) was reported for the first time [31]. The size of the whole genome is $28.45 \mathrm{Mb}$ and is assembled into 68 scaffolds. By comparing the published genome of A. cristatus GZAAS 20.1005, it was found that the basic characteristics of the two genomes were similar; however, slight differences may also be possible among variations (Table 1). Genome-wide comparison of orthologous genes analysis of E1 and GZAAS 20.1005 is shown in Figure 3a. Two strains shared 8511 orthologous gene clusters. Notably, while the overall number of predicted genes was close for both strains (Table 1), there were 7 gene clusters unique to strain E1 and 45 clusters unique to strain 20.1005 (Figure 3a), suggestive of potentially relevant differences between the two strains.

a
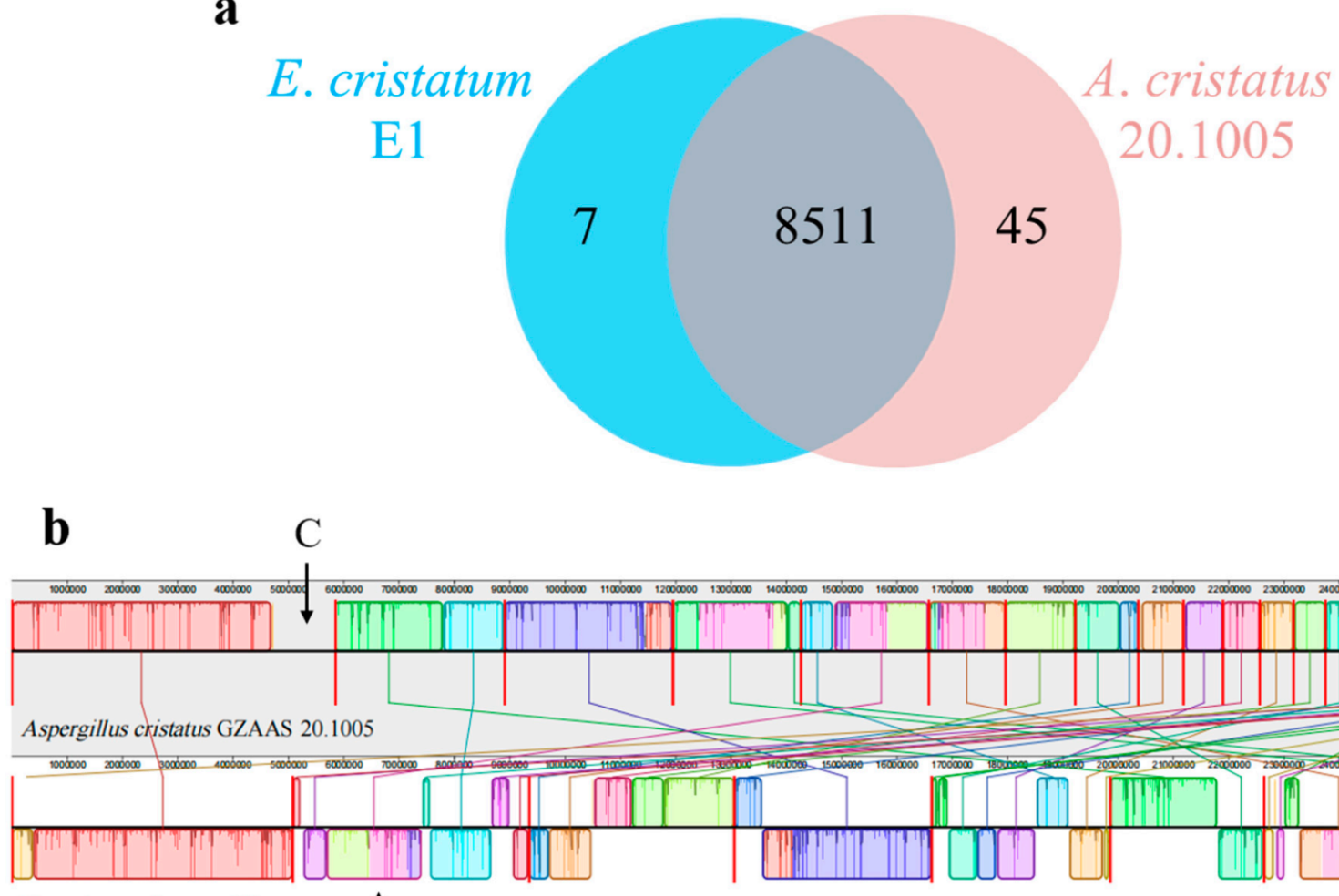

$\mathrm{C}$
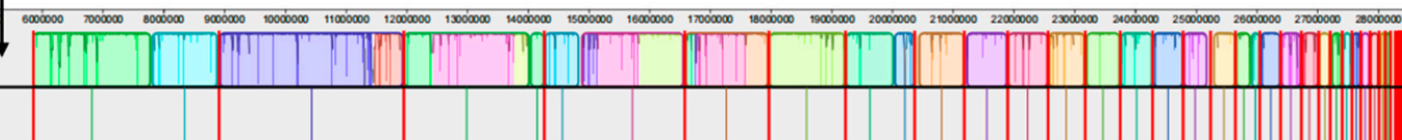

1005
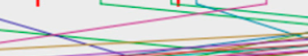

Eurotium cristatum E1

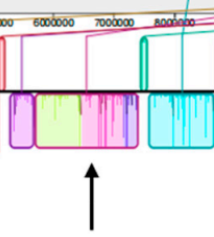

A

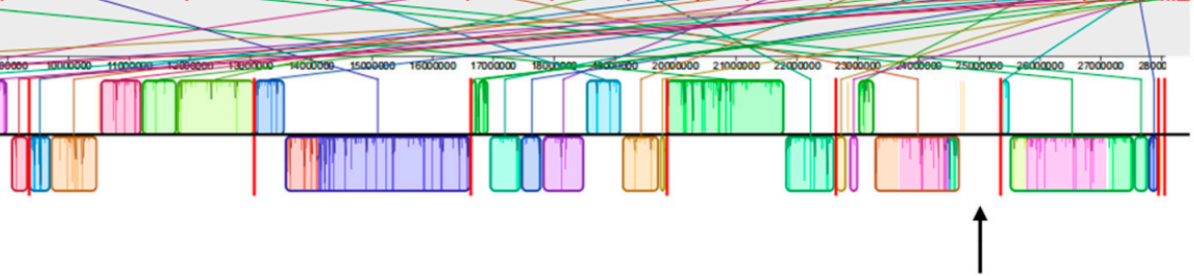

B

Figure 3. Comparative analysis of Eurotium cristatum E1 and Aspergillus cristatus GZAAS 20.1005. (a) Venn diagram illustrating the overlap of shared (core) and strain-specific (accessory) protein coding genes in the genomes of E. cristatum E1 and A. cristatus GZAAS 20.1005. (b) Each contiguously colored box is a locally collinear block (LCB), represent homologous regions with another genome without rearrangement. Lines between two genomes trace each orthologous LCB through every genome. LCBs below a genome's center line are in the reverse complement orientation relative to the reference genome. The bold red lines represent the boundary of contig.

Then, the collinearity analysis between E. cristatum E1 and A. cristatus GZAAS 20.1005 was performed by MAUVE. Results showed that the E1 genome was highly homologous 
to the GZAAS 20.1005 genome, but there were still many sequence rearrangement events (Figure $3 b$ ). These events were illustrated by the crossing lines that link locally collinear blocks (LCBs), which were calculated by MAUVE to identify conserved segments that appear to be internally free from genome rearrangements. The blocks below the center line in the E1 genome suggest the presence of inversion and translocation, such as A LCBs, between two genomes. Moreover, the insertions and deletions occurred in D and E LCBs; while the insertion and inversion of short gene fragments implied that genetic recombination might have occurred during the evolution process of two strains.

\subsection{Analysis the Biosynthesis Gene Clusters of Secondary Metabolites}

Genes that participate in the same secondary metabolic pathway typically reside next to each other in fungal genomes and form a biosynthetic gene cluster (BGC). BGC contains genes encoding all enzymes that are required to produce an SM as well as pathway-specific regulatory genes. The use of the antibiotics and Secondary Metabolite Analysis Shell (antiSMASH, 5.0) enabled the prediction of 34 BGCs potentially capable of producing a diverse array of metabolites (Table 2). Only 6 of these BGCs share any homology to those deposited in the "Minimum Information about a Biosynthetic Gene Cluster" (MIBiG) database, suggesting E. cristatum may possess a unique and unknown secondary metabolite production mechanism.

Table 2. Secondary metabolites gene clusters in Eurotium cristatum E1.

\begin{tabular}{|c|c|c|c|c|c|c|}
\hline Cluster & Contig & Gene Cluster Type & Backbone Enzymes & Predicted Products & Chemical Formulation & Similarity \\
\hline BGC1 & Contig1 & t1pks & PKS & - & & \\
\hline BGC2 & Contig2 & t1pks & PKS & TAN-1612 & & $60 \%$ \\
\hline BGC3 & Contig2 & t1pks & PKS & - & & \\
\hline BGC4 & Contig3 & t1pks & PKS & - & & \\
\hline BGC5 & Contig3 & t1pks & PKS & - & & \\
\hline BGC6 & Contig4 & t1pks & PKS & Naphthopyrone & & $100 \%$ \\
\hline BGC7 & Contig4 & t1pks & PKS & - & & \\
\hline BGC8 & Contig4 & tlpks & PKS & - & & \\
\hline BGC9 & Contig6 & t1pks & PKS & - & & \\
\hline BGC10 & Contig7 & t1pks & PKS & Cornexistin & & $9 \%$ \\
\hline BGC11 & Contig2 & nrps & NRPS & - & & \\
\hline BGC12 & Contig5 & nrps & NRPS & - & & \\
\hline BGC13 & Contig5 & nrps & NRPS & - & & \\
\hline BGC14 & Contig5 & nrps & NRPS & - & & \\
\hline BGC15 & Contig6 & nrps & NRPS & - & & \\
\hline BGC16 & Contig8 & nrps & NRPS & - & & \\
\hline BGC17 & Contig8 & nrps & NRPS & - & & \\
\hline BGC18 & Contig6 & t1pks-nrps & PKS- NRPS & 6-methylsalicylic acid & & $100 \%$ \\
\hline BGC19 & Contig6 & Indole-t1pks & PKS & Neurosporin A & & $20 \%$ \\
\hline BGC20 & Contig8 & Indole-nrps & NRPS & - & & \\
\hline BGC21 & Contig2 & Terpene & & - & & \\
\hline BGC22 & Contig5 & Terpene & & - & & \\
\hline BGC23 & Contig5 & Terpene & & - & & \\
\hline BGC24 & Contig7 & Terpene & & - & & \\
\hline
\end{tabular}


Table 2. Cont.

\begin{tabular}{|c|c|c|c|c|c|c|}
\hline Cluster & Contig & Gene Cluster Type & Backbone Enzymes & Predicted Products & Chemical Formulation & Similarity \\
\hline BGC25 & Contig8 & Terpene & & Clavaric acid & & $66 \%$ \\
\hline BGC26 & Contig3 & Siderophore & & - & & \\
\hline BGC27 & Contig3 & Other & & - & & \\
\hline BGC28 & Contig3 & Other & & - & & \\
\hline BGC29 & Contig3 & Other & & - & & \\
\hline BGC30 & Contig3 & Other & & - & & \\
\hline BGC31 & Contig4 & Other & & - & & \\
\hline BGC32 & Contig5 & Other & & - & & \\
\hline BGC33 & Contig6 & Other & & - & & \\
\hline BGC34 & Contig8 & Other & & - & & \\
\hline
\end{tabular}

The predicted SM clusters are defined according to their "backbone enzymes", which can generate the carbon skeleton of the putative SM. In E. cristatum E1, 34 BGCs can be classified into 6 kinds of categories, non-ribosomal peptide synthetase (NRPS) clusters, type I polyketide synthase (PKS) clusters, terpene clusters, hybrid clusters, siderophore clusters and other clusters, respectively. Ten BGCs contain a gene coding for PKS enzymes, 7 BGCs contain a gene coding for NRPS enzymes and 3 BGCs are hybrid clusters containing genes coding for both PKS or NRPS enzymes. In total, twenty BGCs are related to PKS or NRPS. These results suggest that E. cristatum E1 has the potential ability to produce abundant secondary metabolites, especially polyketides and non-ribosomal peptides.

\subsection{Genomic Distribution of PKS Genes}

Previous studies on secondary metabolites produced by E. cristatum have shown that E. cristatum can produce many kinds of polyketides. PKS is the key enzyme that catalyzes the biosynthesis of polyketides. Fungal PKSs are very large multi-enzymes and contain different enzymatic domains and each domain is responsible for a different function or reaction. Nevertheless, the minimal structure of PKS only requires the KS, AT, and ACP domains [32,33]. Fungal PKS belongs to the iterative type I PKS and has a set of iteratively acting domains responsible for the catalysis of every cycle of polyketide chain elongation.

The above analysis of E. cristatum E1 genome revealed that this fungus encodes 12 polyketide synthases (PKS, Table 3 and Figure 2), of which 6 are highly reducing (HRPKS, synthases with enoyl-reductase, keto-reductase, and dehydratase domains), 5 nonreducing (NR-PKS, synthases with no reducing domains), and 1 partially reducing (PR-PKS, synthases with no ER domains) (Figure 4).

Table 3. Summary of putative PKS genes in the Eurotium cristatum E1 genome.

\begin{tabular}{|c|c|c|c|c|c|c|}
\hline Type & Number & PKS ID & $\begin{array}{l}\text { Amino } \\
\text { Acids }\end{array}$ & Homologs and Related Description & $\begin{array}{l}\text { Sequence } \\
\text { Identity }\end{array}$ & BGC ID—Scaffold \\
\hline \multicolumn{7}{|l|}{ hrPKS } \\
\hline & 1 & A1483 & 2643 & $\begin{array}{l}\text { Lovastatin diketide synthase LovF } \\
\text { (GenBank: GAQ02995.1) }\end{array}$ & $54 \%$ & BGC01—scaffold1 \\
\hline & 2 & A2153 & 2478 & $\begin{array}{l}\text { Beta-ketoacyl synthase } \\
\text { (GenBank: CDM30483.1) }\end{array}$ & $56 \%$ & BGC03—scaffold2 \\
\hline & 3 & A5285 & 2901 & $\begin{array}{l}\text { Carboxylesterase type B } \\
\text { (GenBank: OOO04444.1) }\end{array}$ & $56 \%$ & BGC08—scaffold4 \\
\hline & 4 & A6633 & 2489 & $\begin{array}{c}\text { Acyl transferase/acyl } \\
\text { hydrolase/lysophospholipase } \\
\text { (GenBank: KGO38831.1) }\end{array}$ & $56 \%$ & BGC09—scaffold6 \\
\hline & 5 & A7192 & 2462 & $\begin{array}{l}\text { polyketide synthase } \\
\text { (GenBank: EYE95336.1) }\end{array}$ & $93 \%$ & BGC19—scaffold6 \\
\hline
\end{tabular}


Table 3. Cont.

\begin{tabular}{|c|c|c|c|c|c|c|}
\hline Type & Number & PKS ID & $\begin{array}{l}\text { Amino } \\
\text { Acids }\end{array}$ & Homologs and Related Description & $\begin{array}{l}\text { Sequence } \\
\text { Identity }\end{array}$ & BGC ID—Scaffold \\
\hline \multicolumn{7}{|l|}{ hrPKS } \\
\hline & 6 & A7789 & 2508 & $\begin{array}{l}\text { Lovastatin diketide synthase LovF } \\
\text { (GenBank: GAQ05228.1) }\end{array}$ & $53 \%$ & BGC10—scaffold7 \\
\hline \multicolumn{7}{|c|}{ (1) } \\
\hline & 7 & A2490 & 1778 & $\begin{array}{c}\text { Monodictyphenone synthesis protein } \\
\text { mdpG (GenBank: Q5BH30.1) }\end{array}$ & $53 \%$ & BGC02—scaffold2 \\
\hline & 8 & A3180 & 3237 & $\begin{array}{c}\text { Mycophenolic acid synthesis protein mapC } \\
\text { (GenBank: F1DBA9.1) }\end{array}$ & $46 \%$ & BGC04—scaffold3 \\
\hline & 9 & A4077 & 2117 & $\begin{array}{l}\text { Beta-ketoacyl synthase N-terminal domain } \\
\text { family protein (GenBank: OWW34975.1) }\end{array}$ & $61 \%$ & BGC05—scaffold3 \\
\hline & 10 & A4569 & 1571 & $\begin{array}{c}\text { PKS16 protein (GenBank: EYE96821.1) } \\
\text { Conidial yellow pigment }\end{array}$ & $76 \%$ & BGC06—scaffold4 \\
\hline & 11 & A5054 & 2148 & $\begin{array}{l}\text { biosynthesis polyketide synthase } \\
\text { (GenBank: OOQ85606.1) }\end{array}$ & $71 \%$ & BGC07—scaffold4 \\
\hline prPKS & 12 & A6985 & 1778 & $\begin{array}{l}\text { 6-methylsalicylic acid synthase MsaS } \\
\text { (GenBank: EYE91246.1) }\end{array}$ & $88 \%$ & BGC18—scaffold6 \\
\hline
\end{tabular}

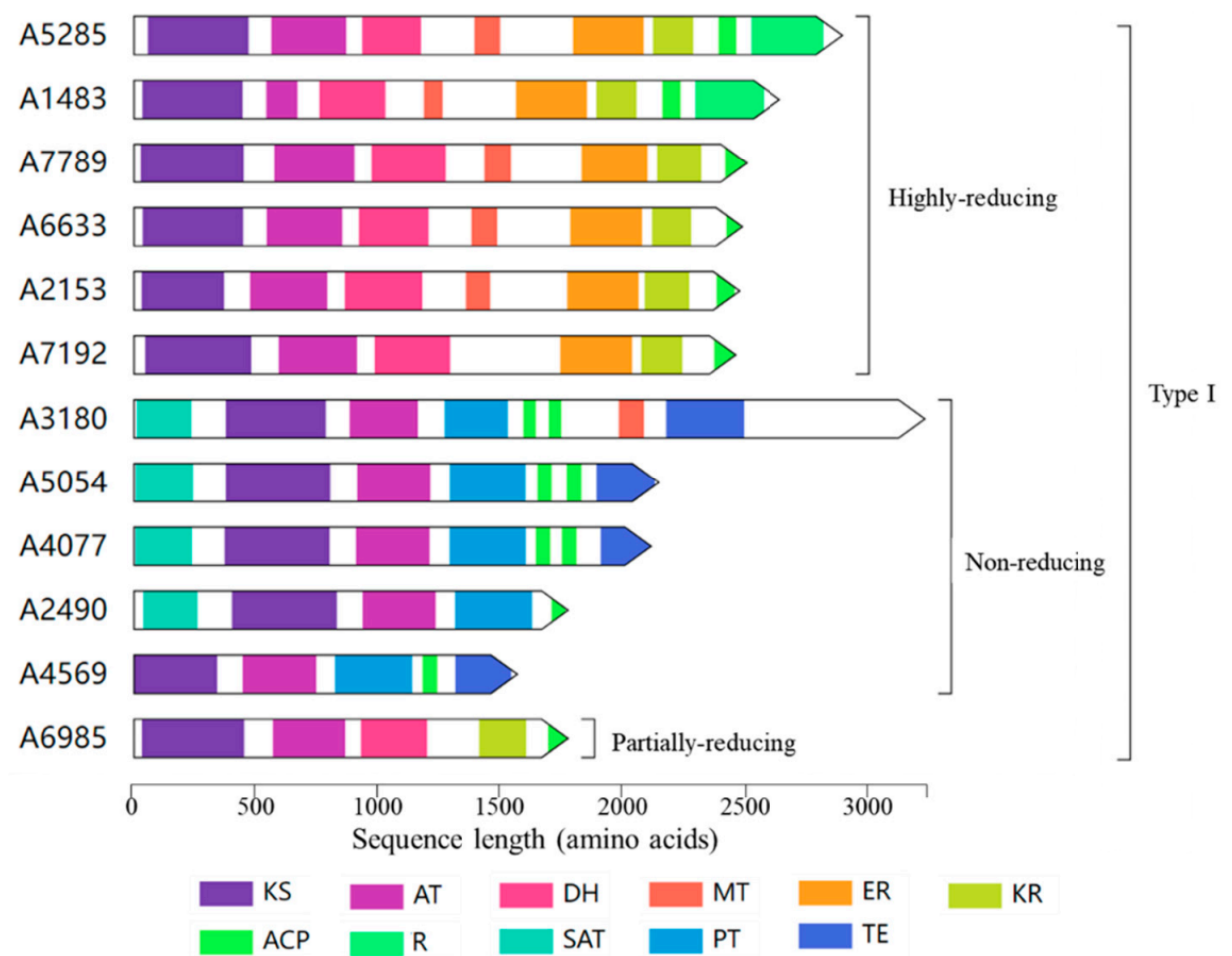

Figure 4. Domain arrangements of twelve PKS genes in the Eurotium cristatum E1 genome. According to the reduction degree, fungal PKS enzymes can be further classified into highly reducing PKS (HR-PKS, with DH, KR, and ER domains), partially reducing PKS (PR-PKS, no ER domains), and non-reducing PKS (NR-PKS, no DH, KR and ER domains). $\beta$-ketosynthase: KS; Acyltransferase: AT; Dehydratase: DH; Methyl transferase: MT; Enoylreductase: ER; Ketoacyl reductase: KR; Acyl carrier protein: ACP; Reductase: R; Starter unit ACP transacylase: SAT; Product template: PT; Thioesterase: TE.

The homologous genes of 12 PKS genes were obtained by NCBI BlastP software and are shown in Table 3. However, only two genes, A6985 and A7192, were found with highly similar homologous sequences at the amino acid level, 88\% and 93\%, respectively. A6985 is responsible for the biosynthesis of 6-methylsalicylic acid, and $A 7192$ is involved in the 
biosynthesis of flavoglaucin and its congeners. Other PKSs showed limited sequence homology against current characterized PKSs. This indicated that many potential polyketides have not been discovered in E. cristatum E1. Much more attention should be paid to explore the function of uncharacterized PKSs, which is meaningful for understanding the biological characteristics of E. cristatum E1.

\subsection{The Relative Expression Level Analysis of PKS Genes}

Although 12 PKS genes in E. cristatum E1 have been identified, it is not known whether these genes can synthesize the related secondary products. Therefore, quantitative realtime PCR (qRT-PCR) was performed to measure the expression level of the predicted PKS genes. The results revealed that all genes were active, but the expression level of these genes was significantly different (Supplementary Figure S3). The expression level of the A7789 (lovastatin) gene was the highest among all the PKS genes. Furthermore, the $A 2490$ (Emodin) and $A 7192$ (flavoglaucin) genes were also highly expressed. These results indicate that the amount of related secondary products synthesized by three genes was very high. The expression level of $A 3180$ was the lowest.

\subsection{Detection of Secondary Metabolites Produced by Eurotium cristatum E1}

Since all the 12 predicted PKS genes were transcribed, ultra-performance liquid chromatography (UPLC) and UPLC-tandem mass spectrometry (UPLC-MS/MS) were performed to identify the secondary metabolites produced by E. cristatum E1. Ten metabolites were found and identified, including citreorosein, emodin, physcion, echinulin, isoaspergin, dihydroauroglaucin, iso-dihydroauroglaucin, aspergin, flavoglaucin, and auroglaucin (Supplementary Figure S4). The identification of emodin, physcion, and flavoglaucin was confirmed by comparison with standards, and other compounds were identified by the comparison of their spectral data with those reported in the literature (Table 4, Supplementary Figures S5 and S6).

Table 4. Molecular weights and UV-Vis spectrum of secondary metabolites produced by Eurotium cristatum E1.

\begin{tabular}{|c|c|c|c|c|c|}
\hline \multirow[b]{2}{*}{ Num } & \multirow[b]{2}{*}{ Compounds } & \multicolumn{3}{|c|}{ UPLC-MS/MS } & \multirow[b]{2}{*}{ UV Chromatogram } \\
\hline & & $\begin{array}{c}\mathbf{m} / \mathbf{z} \\
\left([\mathbf{M}+\mathbf{H}]^{+}\right)\end{array}$ & $\begin{array}{c}\mathbf{m} / \mathbf{z} \\
\left([\mathbf{M}-\mathbf{H}]^{-}\right)\end{array}$ & $\mathrm{m} / \mathbf{z}$ & \\
\hline 1 & Isoaspergin & 303.141 & 301.164 & 302.152 & \\
\hline 2 & Dihydroauroglaucin & 301.164 & 299.314 & 300.239 & \\
\hline 3 & $\begin{array}{c}\text { Iso- } \\
\text { dihydroauroglaucin }\end{array}$ & 300.59 & 298.932 & 299.761 & \\
\hline 4 & Aspergin & 303.97 & 301.291 & 302.630 & \\
\hline 5 & Flavoglaucin & 304.799 & 302.949 & 303.874 & $\bigcap^{248}$ \\
\hline
\end{tabular}


Table 4. Cont.

\begin{tabular}{|c|c|c|c|c|c|}
\hline \multirow[b]{2}{*}{ Num } & \multirow[b]{2}{*}{ Compounds } & \multicolumn{3}{|c|}{ UPLC-MS/MS } & \multirow[b]{2}{*}{ UV Chromatogram } \\
\hline & & $\begin{array}{c}\mathrm{m} / \mathrm{z} \\
\left([\mathrm{M}+\mathrm{H}]^{+}\right)\end{array}$ & $\begin{array}{c}\mathbf{m} / \mathbf{z} \\
\left([\mathbf{M}-\mathbf{H}]^{-}\right)\end{array}$ & $\mathrm{m} / \mathrm{z}$ & \\
\hline 6 & Auroglaucin & 299.123 & 297.083 & 298.103 & \\
\hline 7 & Citreorosein & 286.688 & 284.902 & 285.795 & \\
\hline 8 & Emodin & 270.681 & 268.959 & 269.82 & \\
\hline 9 & Physcion & 285.872 & 283.831 & 284.851 & 206.5285 .5 \\
\hline 10 & Echinulin & 462.297 & 460.129 & 461.213 & $\stackrel{277.1}{1.2}$ \\
\hline
\end{tabular}

According to the predicted results of the function of PKS genes and their gene clusters, E. cristatum E1 can also produce many potential compounds such as lovastatin, 6-methylsalicylic acid, mycophenolic acid, but these compounds were not detected, so the secondary metabolites produced by E. cristatum need to be further studied.

\subsection{Putative Emodin Biosynthetic Gene Cluster in Eurotium cristatum E1}

Because of its very early discovery as a fungal metabolite and its structural proof by synthesis in 1924, emodin, an anthraquinone compound, plays a central role in the secondary metabolites of fungi [34]. Emodin is a polyketide and is synthesized by the regulation of NR-PKS and its cluster. In addition, a large number of studies have found that emodin is only an intermediate in this pathway, which enables the synthesis of multiple different end products, such as geodin, ravenelin, secalonic acids, monodictyphenone, etc. [35-38].

Only three intermediates of the emodin pathway, emodin, citreorosein, and physcion, were discovered in E. cristatum E1. In our previous study, A2490 was proposed to regulate the biosynthesis of monodictyphenone, but at present, this compound was not found in E1. Thus, bioinformatics tools were used to speculate possible compounds, the function of genes in the $A 2490$ gene cluster was predicted (as shown in Table S3). The length of the A2490 gene cluster was $44.8 \mathrm{~kb}$, which contains 17 genes. Then, this cluster was compared with the known emodin-related gene clusters reported in previous reports. Only two genes, A2489 and $A 2490$, encoding metallo-beta-lactamase domain protein and polyketide synthase, found homologous genes (as shown in Figure 5). This consequence cannot confirm which end products can be synthesized by E. cristatum E1. Therefore, further research is needed on the end products produced by E. cristatum E1.

\subsection{Putative Flavoglaucin Biosynthetic Gene Cluster in Eurotium cristatum E1}

Flavoglaucin and its derivatives are a type of benzaldehyde derivatives that contain a C7 alkyl side chain with several double bonds or oxygenated substituents in their basic skeletons. Feeding experiments in 1978 confirmed that the biosynthesis of flavoglaucin is regulated by PKS and modified by isoprenylation [39]. The proposed biosynthetic pathway of flavoglaucin and its congeners was published in 2020 [40]. It has been discovered these 
compounds have many functions, such as antioxidant and antitumor activity [41]. The predicted function of PKS genes suggests that the A7192 gene in E. cristatum E1 may be responsible for the biosynthesis of these compounds. Furthermore, the function of genes in the $A 2490$ gene cluster was predicted (as shown in Table S4). The length of the A7192 gene cluster was $49.7 \mathrm{~kb}$, which contains 16 genes. Then, the comparison between this cluster and the known flavoglaucin gene cluster was performed [40]. Pairwise amino acid alignments with the predicted proteins in this BGC revealed a well-conserved PKS, P450, prenyltransferase, FAD-binding oxidoreductase, a transcription factor as well as three short-chain dehydrogenases. The length and the number of genes involved in the two gene clusters were very different (Figure 6). However, the cultivation of E1 and UPLC analysis confirmed its capability to produce flavoglaucin and its derivatives. Therefore, further studies are necessary to confirm whether the biosynthesis pathway of flavoglaucin and its derivatives in E. cristatum E1 is consistent with the reported pathway.

Endocrocin - A. fumigatus Af293

Trypacidin - A. fumigatus Af293

Geodin - A. terreus NIH2624

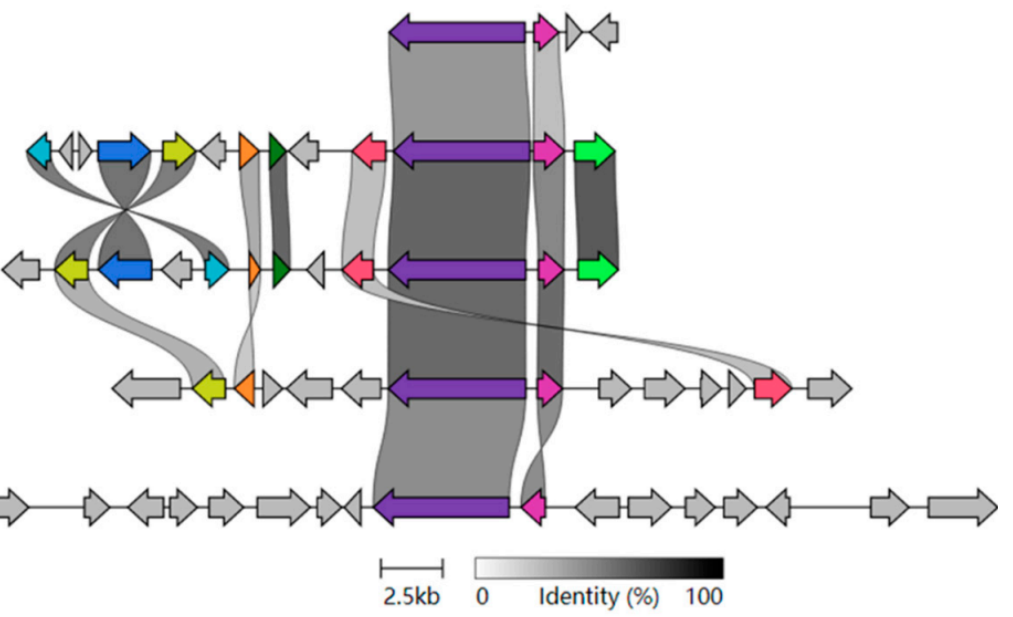

Polyketide synthase

Toxin biosynthesis protein

Gluthathione-S-transferase
Metallo-beta-lactamase

Bayer Villiger-type oxidase

SAM-dependent-methyltransferase
Toxin biosynthesis regulatory protein AflJ

O-methyl transferase

Extracellular dihydrogeodin oxidase/laccase

Figure 5. Comparison of emodin gene cluster in Eurotium cristatum E1 and other known species. The gene cluster used for comparison are from A. fumigatus Af293, A. terreus NIH2624, and A. nidulans FGSC A4, which have a complete emodin-related gene cluster. Each gene is indicated by an arrow. The homologous genes are shown in the same color, and other genes in gray. The genes of $A 2490$ gene cluster in E. cristatum E1 from left to right: A2499, A2498, A2497, A2495, A2494, A2493, A2492, A2491, A2490, A2489, A2488, A2487, A2486, A2484, A2483, A2482, A2481.

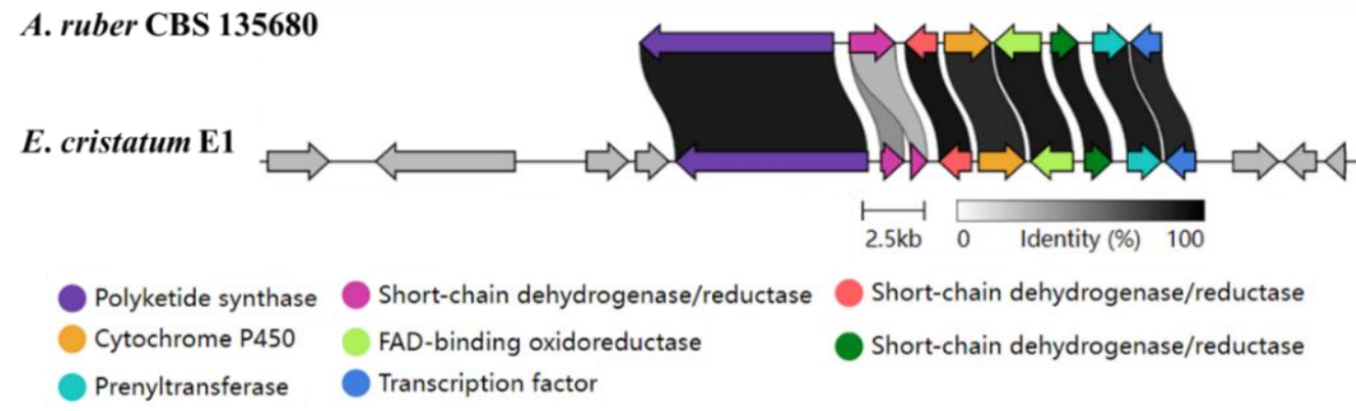

Figure 6. The comparison of flavoglaucin gene cluster in Eurotium cristatum E1 and fog cluster in A. ruber CBS 135680. Each gene is indicated by an arrow. The homologous genes are shown in the same color, and other genes in gray. The genes of $A 7192$ gene cluster in Eurotium cristatum E1 from left to right: A7187, A7189, A7190, A7191, A7192, A7193, A7194, A7195, A7196, A7197, A7198, A7200, A7202, A7203, A7204, A7205. 


\section{Discussion}

In this study, genome-wide sequencing was performed on E. cristatum E1, which is the dominant microorganism involved in a traditional fermented food-Fuzhuan brick tea. The resulting assembly was $28.06 \mathrm{Mb}$ and comprised of 9 contigs. Analysis of the KOG functional classification of the proteins indicated that among the 2248 genes, $844(37.5 \%)$ genes were assigned to functional annotations with significant biological significance. The results also showed that the genes were outstanding in energy production and conversion, amino acid transport and metabolism, carbohydrate transport and metabolism, secondary metabolites biosynthesis, transport and catabolism, etc., which might suggest the advantages of this strain for producing abundant metabolites.

The cost of genome sequencing has decreased rapidly, due to the invention of nextgeneration sequencing (NGS) technologies, e.g., the Pacific Biosciences Single Molecule Real-Time (PacBio SMRT) platform [42]. Particularly, the Illumina short-read-based genome assemblies frequently missed large fragments of giant genes encoding PKS and NRPS, which play an important key role in studying the secondary metabolites of fungi [43]. However, next-generation sequencing technologies have solved this problem and allowed researchers to gain a deeper understanding of the molecular and genetic mechanisms of fungi [44]. To date, there is only one complete annotated genome of E. cristatum available in the NCBI database. The whole genome of A. cristatus (A. cristatus GZAAS 20.1005, GenBank: GCA_001717485.1), published in 2013, was obtained by the Illumina Hiseq ${ }^{\mathrm{TM}} 2000$ system and assembled into 68 scaffolds [31]. The number of scaffolds is much higher than that of E1, which fits the longer reading advantage of NGS [36]. In addition, the comparative analysis of collinearity between genomes not only revealed the rearrangement, inversion, and translocation between two genomes but also found the absence of long fragments in both genomes. These results implied that genetic recombination may have occurred during the evolution process of the two strains.

E. cristatum is a kind of filamentous fungi, which is renowned for producing a wide variety of secondary metabolites with various bioactivities [11]. With the rapid development of bioinformatics, genome mining for screening gene clusters is a new method for investigating the SMs produced by a fungus [45]. BGC analysis of E. cristatum E1 discovered, out of 34 BGCs, that only 6 BGCs showed different levels of similarity with known gene clusters. Furthermore, only 3 BGCs showed more than $80 \%$ similarity to known BGCs. Thus, E. cristatum E1 might present a higher potential for producing new metabolites. Among the 34 BGCs, 20 BGCs were related to PKS or NRPS, which might reflect the potential of this fungi to produce various polyketides and non-ribosomal peptides.

Polyketides are very important secondary metabolites with great diversity in their structures, functional diversities, and a wide range of biological activities, which are regulated by PKS [10]. It is worth mentioning that the number of PKS genes in E. cristatum E1 was lower than that in other Aspergillus species (Supplementary Figure S7) [46,47]. It is very strange that there are only 12 PKS genes in E. cristatum E1 because based on previous studies, E. cristatum E1 has a stronger ability to produce polyketides such as emodin and flavoglaucin $[12,14]$. In addition, the qRT-PCR results further demonstrated that these genes were expressed and had the ability to synthesize related compounds.

However, the above results only demonstrated that E. cristatum E1 can produce these compounds at the genomic level. Subsequently, the secondary metabolites produced by E. cristatum E1 were analyzed by UPLC and UPLC-MS/MS. Ten compounds were identified, but only two compounds, emodin and flavoglaucin, have been found in the PKS genes that might be responsible for their synthesis. Furthermore, based on the bioinformatics analysis results, compounds such as lovastatin, 6-methylsalicylic acid, mycophenolic acid, etc., were predicted. However, compared to the standards, lovastatin and mycophenolic acid could not be detected in the above UPLC and UPLC-MS/MS analysis; therefore, further research is needed to verify the secondary metabolites produced by E. cristatum E1.

Emodin, as an important metabolite, has been studied since 1924. It has many functions, such as antibacterial, antiviral, antioxidant, etc. [34]. Emodin is only an intermediate, 
it can be converted into different end-products, depending on the Aspergillus sp. [48]. However, only emodin, citreorosein, and physcion were isolated from E. cristatum E1. In the emodin biosynthesis pathway, citreorosein and physcion are intermediate products, which are produced after the synthesis of emodin. Different compounds are then synthesized through a series of other reactions [49]. Compared with known emodin-related gene clusters, only A2489 and A2490 had found their homologous genes; while, according to previous studies, the presence of these two genes can only produce emodin [36,37]. From the gene clusters map, the length of the emodin gene cluster is much longer than other clusters. It contains 17 genes, whereas other clusters contain at most 13 genes, and only four genes are involved in the endocrocin gene cluster. The similarity between the $A 2490$ gene cluster and the known gene cluster is very low. Whether citreorosein and physcion are intermediate products or end-products produced by E. cristatum E1 needs further study. In general, combined with the results of gene cluster alignment and secondary metabolites analysis, there may be a different emodin-related pathway that exists in E. cristatum E1. Further studies are needed to confirm this hypothesis.

Flavoglaucin is a class of benzaldehyde derivatives that contain a variety of derivatives, which occur widely in Aspergillus sp. [39]. It was discovered in the last century, but the biosynthetic pathway was only reported in 2020 [50]. In 2020, the biosynthetic gene cluster of flavoglaucin in Aspergillus ruber was proposed [40,50]. Furthermore, the comparison between the proposed BGC in E1 and the known flavoglaucin gene cluster showed that the number of genes varies enormously (16 vs. 8). However, the similarity of PKS genes and the eight genes downstream of BGC at the amino acid level was more than $85 \%$. In addition, $A$. ruber can produce six kinds of flavoglaucin and congeners, including isoaspergin, dihydroauroglaucin, aspergin, flavoglaucin, auroglaucin, and 2-(1',5'-heptadienyl)-3,6-dihydroxy-5-(3"-methyl-2"-butenyl) benzaldehyde [40]. However, the analysis of secondary metabolites of E. cristatum E1 found that it cannot produce the last compound, but can produce iso-dihydroauroglaucin. Whether these differences will lead to different biosynthetic pathways in E. cristatum E1 requires further study. The putative emodin and flavoglaucin gene clusters were proposed, but large differences were found by comparison with known gene clusters. However, some related compounds were identified from E. cristatum E1. Furthermore, the biosynthetic pathways of emodin and flavoglaucin need to be proved by several approaches, such as gene knockout, in vitro reaction, and heterologous expression.

Although these results indicate that compounds detected in E. cristatum corresponded to the gene function analysis, the identification of other compounds and PKS genes still needs to be further studied. Firstly, further isolation and identification of secondary metabolites in E. cristatum E1 are needed. Secondly, the development of new bioinformatic tools will help in the identification and annotation of new gene clusters. Moreover, using molecular biological methods, such as gene knockout, is a direct approach to determine the function of genes. Overall, these previous results might be significantly important for understanding E. cristatum E1.

In this work, a combined approach beginning with genome mining for screening, followed by transcript-level expression analysis, and the identification of products from wildtype fungi, was used to systematically study the polyketides produced by E. cristatum E1. The function of PKS genes was analyzed after obtaining genomic information through whole-genome sequencing, and the possible compounds were speculated. Ten compounds were identified from this strain, in which the biosynthetic gene and its gene cluster responsible for two compounds (emodin and flavoglaucin) were identified. These results demonstrate a higher potential in discovering novel secondary metabolites from E. cristatum E1, and also provide some guidelines into the use of combining bioinformatics tools and the approach of isolating and identifying compounds in the discovery of secondary metabolites. This will provide a good basis for systematically mining SMs resources of Eurotium cristatum and broadening its application fields. 
Supplementary Materials: The following are available online at https://www.mdpi.com/article /10.3390/jof8020193/s1, Figure S1: KOG distribution of predicted proteins from Eurotium cristatum E1 genome, Figure S2: Confirmation of the taxonomic classification of Eurotium cristatum E1, Figure S3: Real-time RT-PCR analysis of the PKS genes in Eurotium cristatum E1, Figure S4: UPLC analysis of Eurotium cristatum E1 extracts, Figure S5: UPLC-MS analysis of Eurotium cristatum E1 extracts, Figure S6: ESIMS spectra in negative mode of flavoglaucin and its derivatives (1-6), citreorosein (7), emodin (8), physion (9) and echinulin (10), Figure S7: The number of PKS genes in some sequenced Aspergillus species, Table S1: Strains and accession information of genes used for phylogenetic tree construction, Table S2: Primers used for qRT-PCR, Table S3: Analysis of A2490 gene cluster in Eurotium cristatum E1, Table S4: Analysis of A7192 gene cluster in Eurotium cristatum E1.

Author Contributions: Conceptualization, X.G., Y.Z. and X.W.; methodology, X.G., Y.Z., J.L., F.C. and Y.S.; software, X.G. and J.L.; analysis of the data, X.G. and Y.Z.; writing-original draft preparation, X.G.; writing-review and editing, X.G., Y.Z. and J.L.; visualization, Y.Z., F.C., X.W. and Y.S.; supervision, X.W., F.C. and Y.S. All authors have read and agreed to the published version of the manuscript.

Funding: This research was funded by the projects of Chinese National Natural Science Foundation (no. 31730068, 31701583 and 31371824), Competitive Program of Hubei Academy of Agricultural Sciences (no. 2016JZXJH01), Projects of Hubei Agricultural Sciences and Technology Innovation Center (no. 2020-620-001-03).

Institutional Review Board Statement: Not applicable.

Informed Consent Statement: Not applicable.

Data Availability Statement: External data sources used in this study are cited in article. The extracted data is available in Supplementary Material.

Acknowledgments: This research was supported by the projects of Chinese National Natural Science Foundation (no. 31730068, 31701583 and 31371824), Competitive Program of Hubei Academy of Agricultural Sciences (no. 2016JZXJH01), Projects of Hubei Agricultural Sciences and Technology Innovation Center (no. 2020-620-001-03).

Conflicts of Interest: No conflict of interest exits in the submission of this manuscript, and manuscript is approved by all authors to be published.

\section{References}

1. Zheng, W.; Wan, X.; Bao, G. Brick dark tea: A review of the manufacture, chemical constituents and bioconversion of the major chemical components during fermentation. Phytochem. Rev. 2015, 14, 499-523. [CrossRef]

2. Ren, C.G. Metabolomics reveals changes in metabolite concentrations and correlations during sexual development of Eurotium cristatum (synonym: Aspergillus cristatus). Mycosphere 2017, 8, 1626-1639. [CrossRef]

3. Liu, G.; Duan, Z.; Wang, P.; Fan, D.; Zhu, C. Purification, characterization, and hypoglycemic properties of eurocristatine from Eurotium cristatum spores in Fuzhuan brick tea. RSC Adv. 2020, 10, 22234-22241. [CrossRef]

4. Rui, Y.; Wan, P.; Chen, G.; Xie, M.; Sun, Y.; Zeng, X.; Liu, Z. Analysis of bacterial and fungal communities by Illumina MiSeq platforms and characterization of Aspergillus cristatus in Fuzhuan brick tea. Lwt 2019, 110, 168-174. [CrossRef]

5. Xu, A.; Wang, Y.; Wen, J.; Liu, P.; Liu, Z.; Li, Z. Fungal community associated with fermentation and storage of Fuzhuan brick-tea. Int. J. Food Microbiol. 2011, 146, 14-22. [CrossRef]

6. Li, Q.; Huang, J.; Li, Y.; Zhang, Y.; Luo, Y.; Chen, Y.; Lin, H.; Wang, K.; Liu, Z. Fungal community succession and major components change during manufacturing process of Fu brick tea. Sci. Rep. 2017, 7, 6407. [CrossRef]

7. Qi, Z.T.; Sun, Z.M. Identification of predominant species in brick tea. Acta Mycol. Sin. 1990, 9, 176-179.

8. Zhang, L.; Zhang, Z.; Zhou, Y.; Ling, T.; Wan, X. Chinese dark teas: Postfermentation, chemistry and biological activities. Food Res. Int. 2013, 53, 600-607. [CrossRef]

9. Fu, D.; Ryan, E.P.; Huang, J.; Liu, Z.; Weir, T.L.; Snook, R.L.; Ryan, T.P. Fermented Camellia sinensis, Fu Zhuan Tea, regulates hyperlipidemia and transcription factors involved in lipid catabolism. Food Res. Int. 2011, 44, 2999-3005. [CrossRef]

10. Cox, R.J.; Skellam, E.; Williams, K. Biosynthesis of Fungal Polyketides. In Physiology and Genetics. The Mycota (A Comprehensive Treatise on Fungi as Experimental Systems for Basic and Applied Research); Anke, T., Schüffler, A., Eds.; Springer: Cham, Switzerland, 2018; Volume 15. [CrossRef]

11. Wiemann, P.; Guo, C.J.; Palmer, J.M.; Sekonyela, R.; Wang, C.C.; Keller, N.P. Prototype of an intertwined secondary-metabolite supercluster. Proc. Natl. Acad. Sci. USA 2013, 110, 17065-17070. [CrossRef] 
12. Shi, J.; Liu, J.; Kang, D.; Huang, Y.; Kong, W.; Xiang, Y.; Zhu, X.; Duan, Y.; Huang, Y. Isolation and Characterization of Benzaldehyde Derivatives with Anti-Inflammatory Activities from Eurotium cristatum, the Dominant Fungi Species in Fuzhuan Brick Tea. ACS Omega 2019, 4, 6630-6636. [CrossRef]

13. Zou, X.; Li, Y.; Zhang, X.; Li, Q.; Liu, X.; Huang, Y.; Tang, T.; Zheng, S.; Wang, W.; Tang, J. A new prenylated indole diketopiperazine alkaloid from Eurotium cristatum. Molecules 2014, 19, 17839-17847. [CrossRef]

14. Peng, X.; Liang, F.; Li, D.; Chen, Y.; Tao, M.; Zhang, W.; Yunlin, Z. Secondary metabolites of Eurotium cristatum from Fu Brick Tea and their biological activities. Chin. Tradit. Herb. Drugs 2013, 44, 1881-1886.

15. Slack, G.J.; Puniani, E.; Frisvad, J.C.; Samson, R.A.; Miller, J.D. Secondary metabolites from Eurotium species, Aspergillus calidoustus and $A$. insuetus common in Canadian homes with a review of their chemistry and biological activities. Mycol Res. 2009, 113, 480-490. [CrossRef]

16. Liu, Q.; Xie, N.; He, Y.; Wang, L.; Shao, Y.; Zhao, H.; Chen, F. MpigE, a gene involved in pigment biosynthesis in Monascus ruber M7. Appl. Microbiol. Biotechnol. 2013, 98, 285-296. [CrossRef]

17. Wingett, S.W.; Andrews, S. FastQ Screen: A tool for multi-genome mapping and quality control. F1000Res 2018, 7, 1338. [CrossRef]

18. Ardui, S.; Ameur, A.; Vermeesch, J.R.; Hestand, M.S. Single molecule real-time (SMRT) sequencing comes of age: Applications and utilities for medical diagnostics. Nucleic Acids Res. 2018, 46, 2159-2168. [CrossRef]

19. Stanke, M.; Diekhans, M.; Baertsch, R.; Haussler, D. Using native and syntenically mapped cDNA alignments to improve de novo gene finding. Bioinformatics 2008, 24, 637-644. [CrossRef]

20. Sayers, E.W.; Bolton, E.E.; Brister, J.R.; Canese, K.; Chan, J.; Comeau, D.C.; Connor, R.; Funk, K.; Kelly, C.; Kim, S.; et al. Database resources of the national center for biotechnology information. Nucleic Acids Res. 2022, 50, D20-D26. [CrossRef]

21. Tamura, K.; Peterson, D.; Peterson, N.; Stecher, G.; Nei, M.; Kumar, S. MEGA5: Molecular evolutionary genetics analysis using maximum likelihood, evolutionary distance, and maximum parsimony methods. Mol. Biol. Evol. 2011, 28, 2731-2739. [CrossRef]

22. Emms, D.M.; Kelly, S. OrthoFinder: Phylogenetic orthology inference for comparative genomics. Genome Biol. 2019, $20,238$. [CrossRef] [PubMed]

23. Darling, A.C.; Mau, B.; Blattner, F.R.; Perna, N.T. Mauve: Multiple alignment of conserved genomic sequence with rearrangements Genome Res. 2004, 14, 1394-1403. [CrossRef] [PubMed]

24. Blin, K.; Shaw, S.; Steinke, K.; Villebro, R.; Ziemert, N.; Lee, S.Y.; Medema, M.H.; Weber, T. antiSMASH 5.0: Updates to the secondary metabolite genome mining pipeline. Nucleic Acids Res. 2019, 47, W81-W87. [CrossRef]

25. Medema, M.H.; Kottmann, R.; Yilmaz, P.; Cummings, M.; Biggins, J.B.; Blin, K.; de Bruijn, I.; Chooi, Y.H.; Claesen, J.; Coates, R.C.; et al. Minimum Information about a Biosynthetic Gene cluster. Nat. Chem. Biol. 2015, 11, 625-631. [CrossRef]

26. Mistry, J.; Chuguransky, S.; Williams, L.; Qureshi, M.; Salazar, G.A.; Sonnhammer, E.L.L.; Tosatto, S.C.E.; Paladin, L.; Raj, S.; Richardson, L.J.; et al. Pfam: The protein families database in 2021. Nucleic Acids Res. 2021, 49, D412-D419. [CrossRef] [PubMed]

27. Cameron, L.M. Gilchrist. gamcil/synthaser: Synthaser v1.1.0 (v1.1.0). Zenodo 2020. [CrossRef]

28. Chen, W.; Chen, R.; Liu, Q.; He, Y.; He, K.; Ding, X.; Kang, L.; Guo, X.; Xie, N.; Zhou, Y.; et al. Orange, red, yellow: Biosynthesis of azaphilone pigments in Monascus fungi. Chem. Sci. 2017, 8, 4917-4925. [CrossRef]

29. Gilchrist, C.L.M.; Chooi, Y.H. Clinker \& clustermap.js: Automatic generation of gene cluster comparison figures. Bioinformatics 2021, 37, 2473-2475. [CrossRef]

30. Dohra, H.; Tanaka, K.; Suzuki, T.; Fujishima, M.; Suzuki, H. Draft genome sequences of three Holospora species (Holospora obtusa, Holospora undulata, and Holospora elegans), endonuclear symbiotic bacteria of the ciliate Paramecium caudatum. FEMS Microbiol. Lett. 2014, 359, 16-18. [CrossRef]

31. Ge, Y.; Wang, Y.; Liu, Y.; Tan, Y.; Ren, X.; Zhang, X.; Hyde, K.D.; Liu, Y.; Liu, Z. Comparative genomic and transcriptomic analyses of the Fuzhuan brick tea-fermentation fungus Aspergillus cristatus. BMC Genom. 2016, 17, 1-13. [CrossRef]

32. He, Y.; Wang, B.; Chen, W.; Cox, R.J.; He, J.; Chen, F. Recent advances in reconstructing microbial secondary metabolites biosynthesis in Aspergillus spp. Biotechnol. Adv. 2018, 36, 739-783. [CrossRef]

33. van Dijk, J.W.A.; Guo, C.-J.; Wang, C.C.C. Engineering Fungal Nonribosomal Peptide Synthetase-like Enzymes by Heterologous Expression and Domain Swapping. Org. Lett. 2016, 18, 6236-6239. [CrossRef]

34. Schor, R.; Cox, R. Classic fungal natural products in the genomic age: The molecular legacy of Harold Raistrick. Nat. Product Rep. 2018, 35, 230-256. [CrossRef]

35. Throckmorton, K.; Lim, F.Y.; Kontoyiannis, D.P.; Zheng, W.; Keller, N.P. Redundant synthesis of a conidial polyketide by two distinct secondary metabolite clusters in Aspergillus fumigatus. Environ. Microbiol. 2016, 18, 246-259. [CrossRef]

36. Virolle, M.-J.; Nielsen, M.T.; Nielsen, J.B.; Anyaogu, D.C.; Holm, D.K.; Nielsen, K.F.; Larsen, T.O.; Mortensen, U.H. Heterologous Reconstitution of the Intact Geodin Gene Cluster in Aspergillus nidulans through a Simple and Versatile PCR Based Approach. PLOS ONE 2013, 8, e72871.

37. Sanchez, J.F.; Entwistle, R.; Hung, J.-H.; Yaegashi, J.; Jain, S.; Chiang, Y.-M.; Wang, C.C.C.; Oakley, B.R. Genome-Based Deletion Analysis Reveals the Prenyl Xanthone Biosynthesis Pathway in Aspergillus nidulans. J. Am. Chem. Soc. 2011, 133, 4010-4017. [CrossRef]

38. Chiang, Y.-M.; Szewczyk, E.; Davidson, A.D.; Entwistle, R.; Keller, N.P.; Wang, C.C.C.; Oakley, B.R. Characterization of the Aspergillus nidulans Monodictyphenone Gene Cluster. Appl. Environ. Microbiol. 2010, 76, 2067-2074. [CrossRef]

39. Allen, J.K.; Barrow, K.D.; Jones, A.J.; Hanisch, P. Biosynthesis of Flavoglaucin. Stereochemistry of Aromatic Isoprenylation. J. Chem. Soc. Perkin Trans. 1978, 1, 152-154. [CrossRef] 
40. Nies, J.; Ran, H.; Wohlgemuth, V.; Yin, W.B.; Li, S.M. Biosynthesis of the Prenylated Salicylaldehyde Flavoglaucin Requires Temporary Reduction to Salicyl Alcohol for Decoration before Reoxidation to the Final Product. Org. Lett. 2020, 22, 2256-2260. [CrossRef]

41. Miyake, Y.; Ito, C.; Tokuda, H.; Osawa, T.; Itoigawa, M. Evaluation of flavoglaucin, its derivatives and pyranonigrins produced by molds used in fermented foods for inhibiting tumor promotion. Biosci. Biotechnol. Biochem. 2010, 74, 1120-1122. [CrossRef]

42. Nguyen, C.T.; Bridget, A.F.; Pham, V.T.T.; Nguyen, H.T.; Kim, T.S.; Sohng, J.K. Genome mining Streptomyces sp. KCTC 0041BP as a producer of dihydrochalcomycin. Appl. Microbiol. Biotechnol. 2021, 105, 5023-5037. [CrossRef] [PubMed]

43. Varadarajan, A.R.; Allan, R.N.; Valentin, J.D.P.; Castañeda Ocampo, O.E.; Somerville, V.; Pietsch, F.; Buhmann, M.T.; West, J.; Skipp, P.J.; van der Mei, H.C.; et al. An integrated model system to gain mechanistic insights into biofilm-associated antimicrobial resistance in Pseudomonas aeruginosa MPAO1. Npj Biofilms Microbiomes 2020, 6, 1-17. [CrossRef] [PubMed]

44. Reva, O.N.; Larisa, S.A.; Mwakilili, A.D.; Tibuhwa, D.; Lyantagaye, S.; Chan, W.Y.; Lutz, S.; Ahrens, C.H.; Vater, J.; Borriss, R. Complete genome sequence and epigenetic profile of Bacillus velezensis UCMB5140 used for plant and crop protection in comparison with other plant-associated Bacillus strains. Appl. Microbiol. Biotechnol. 2020, 104, 7643-7656. [CrossRef] [PubMed]

45. Kjaerbolling, I.; Mortensen, U.H.; Vesth, T.; Andersen, M.R. Strategies to establish the link between biosynthetic gene clusters and secondary metabolites. Fungal Genet. Biol. 2019, 130, 107-121. [CrossRef]

46. Lin, S.H.; Yoshimoto, M.; Lyu, P.C.; Tang, C.Y.; Arita, M. Phylogenomic and Domain Analysis of Iterative polyketide synthases in Aspergillus species. Evol. Bioinform. 2012, 8, 373-387. [CrossRef]

47. Amnuaykanjanasin, A.; Phonghanpot, S.; Sengpanich, N.; Cheevadhanarak, S.; Tanticharoen, M. Insect-specific polyketide synthases (PKSs), potential PKS-nonribosomal peptide synthetase hybrids, and novel PKS clades in tropical fungi. Appl. Environ. Microbiol. 2009, 75, 3721-3732. [CrossRef]

48. Frisvad, J.C.; Larsen, T.O. Chemodiversity in the genus Aspergillus. Appl. Microbiol. Biotechnol. 2015, 99, 7859-7877. [CrossRef]

49. Kong, W.; Huang, C.; Shi, J.; Li, Y.; Jiang, X.; Duan, Q.; Huang, Y.; Duan, Y.; Zhu, X. Recycling of Chinese herb residues by endophytic and probiotic fungus Aspergillus cristatus CB10002 for the production of medicinal valuable anthraquinones. Microb. Cell Fact. 2019, 18, 102. [CrossRef]

50. Ran, H.; Li, S.M. Fungal benzene carbaldehydes: Occurrence, structural diversity, activities and biosynthesis. Nat. Prod. Rep. 2020, 38, 240-263. [CrossRef] 